\title{
Perception of Foreign Language Learners in the Use of Internet-Based Tools
}

\author{
Jackielou E.Cansancio, Lovely Ivy C. Rillon, Shareena D. Sowaib, \\ Christian Aron G. Tuppal \\ jackielou.cansancio@umak.edu.ph \\ University of Makati, J.P. Rizal Extension, West Rembo, Makati City 1215, Philippines
}

\begin{abstract}
This study is aimed at understanding the perception of foreign language learners on the use of internet-based tools in learning in general and learning a foreign language in particular. The study is focused on investigating the learners' view on the strengths, significant uses and problems with integrating internet-based tools in classroom learning and personal supplementary learning. A survey was used in collecting data by providing a 35 -item self-assessment questionnaire to a whole class of respondents who are taking a Mandarin language course from the College of Business and Financial Science of the University of Makati. The data collected was analyzed by getting the frequency and mean to determine which strengths, significant uses, and problems with integrating internet-based tools perceived to be true for the learners. Although foreign learners have a generally positive view of integrating internet-based tools in foreign language learning, they are not using it sufficiently.
\end{abstract}

\section{Introduction}

Technology has paved the way for rapid advancement in education. Through the integration of technology, the teaching-learning practices have evolved from traditional classroom discussions with the teacher as the primary source of knowledge to the students having the opportunity to direct their learning. The onset of digital technology provided new learning opportunities and innovative elements to language learning (Evans, M. 2011). This states that through digital technology, a wide range of strategies for learning languages is now available. Letting the students be exposed to this kind of learning platform is an opportunity to explore and try something new in learning. Learning opportunities likewise took a different guise in the form of internet-based tools(IBTs) that catered to the varying learning needs and abilities of the learners. These features of technology made foreign language learning comprehensive and suitable for individual learners. Furthermore, learning a language allows an individual to be involved in effective and creative communication which paves the way for them to participate in real-life situations through the language of a culture. (Moeller A. and Catalano T. 2015). Hence, foreign language students need to be exposed and be immersed in the language they wanted to study for 
them to adapt to the nature of the language. In this regard, the internet opens vast opportunities for students to understand, and to some degree, experience the culture where the language they are trying to learn came from.

With the intention of keeping at par with such progress in education and to address the above mentioned learning needs, the University of Makati therefore vows to integrate the latest technologies available as reiterated in its vision statement: "to mold Makati youth into productive citizens and ITenabled professionals who are exposed to the cutting edge of technology in their areas of specialization". In line with this, the study to be conducted by the researchers aims to understand the learners' perception of utilizing internet-based tools in learning foreign languages; how such tools assist them in effectively understanding, practicing and applying their learning with the main purpose of providing comprehensive findings which will further benefit teachers and the administration. The researches would like to know what types of internet-based tools are currently utilized by the actual learners of different foreign languages in the university. Moreover, the researchers will inquire of the students' perception of the assistance these tools are providing them as they hone their skills in communicating in the language they are learning.

\section{Review of Related Literature}

The advancement of technology in the $21^{\text {st }}$ century world has brought a massive change in the way teaching and learning is done in a language classroom. Before the onset of technology, educators and learners depend heavily on the use of textbooks. This changed in the arrival of internet-based tools.

\section{Internet-Based Tools}

Internet-based tools (IBTs) are materials, applications, and sources that can be accessed through any gadget or device that has an internet connection. However, IBTs are not limited to online tools, it also encompasses applications that can be downloaded and installed in devices. These tools were most often used by learners in looking for learning materials that can supplement their learning and help in creating, simulating and applying their knowledge and skills. Examples of the IBTs that are most commonly used are search engines such as Google, Yahoo!, Microsoft Edge, Opera, and Internet Explorer. Other types of IBT's are those that can be used for creating like Microsoft Word, PowerPoint, and Excel. Online dictionaries, E-books, and simulation games are also included under IBT's. 
A study on the use of technology in English language learning, states that technology helps learners address learning problems by finding effective and meaningful methods which makes them learn the language according to their own pace and self-understanding which in turn creates high motivation in learners for the effective development of their language skills (Ahmadi, M., 2018). It means that utilizing these kinds of learning tools can help the learners maximize their potentials in learning a particular language. Furthermore, through having the necessary knowledge and ampletraining, teachers will have an edge in integrating this tool in teaching languages.

\section{Language Learning}

Language learning as defined by Oxford University Press (2019) is "the learning of any languages or of language itself'. Recent studies prove that IBTs significantly improved the overall communication skills of the learner, specifically, their speaking or oral communication skills. This is attributed to the ability of IBTs to provide second language and foreign language learners with opportunities to interact with the native speakers of their target language. The availability of reliable learning materials also contributed immensely to the development of the reading skills of learners. Translation features of various IBTs make it easier to understand difficult words encountered in their reading. However, with regard to the writing skills of learners, a particular concern was prominent. Learners are becoming less critical in their writing due to the autocorrect feature of most IBTs. This, in turn, lowers their proofreading skills and they tend to commit grammatical mistakes that can affect the credibility of their works (Omar, A. and Miah, M. 2012). Added to this is the fact that the language of the internet is mostly informal which poses a difficulty for students to switch into formal writing, as they were already used to the language of the web. Furthermore, based on Gallo-Crail, R., and Zerwekh, R. (2002), strategies are essential in learning a language because they "enhance students' own learning, and students use them for active, self-directed involvement that is essential for developing communicative competence". This shows the importance of choosing a learning strategy that supports learners' different learning styles making language learning more effective.

\section{Challenges in the use of IBTs}

There were a number of challenges in integrating technology in the classrooms. A study about ICT integration in education categorized thechallenges into three: environmental, cultural and educational 
(Mbodila M., Jones, T., and Muhandji K. 2013). According to the said study, environmental challenges include the absence of buildings and facilities for housing the technology, lack of electricity, and policymakers who doubt the importance of said technology to education. The latter is probably one of the most difficult challenges to overcome since schools were only depending on the policies and support the government provides. Cultural challenges include the problem with language. English is the language of the internet making it challenging to utilize in the schools of countries with multilinguistic backgrounds like India, Pakistan, and South Africa, to name a few. Educational challenges include a lack of trained personnel who will facilitate the integration of technology and the general unpreparedness of the schools. Having the technology without the proper system on how this will be implemented will be futile. In the end, it will just be a waste of resources. Moreover, resistance to change, lack of hardware and guidance to use them, kids-will-know-more-than-me attitude, fear of technology, lack of training opportunities and rigid teaching models are some of the major challenges faced by teachers and school administrators in integrating technology in the classroom (Gupta, P. 2017). These can be attributed to the fact that integration of IBTs requires ample knowledge on how it works, the proper machinery and an overall change of curriculum for it to be efficiently utilized.

Furthermore, upon considering the available resources relating to technologies in foreign language learning, a number of issues arose. First, the researchers noticed the lack of studies in the Philippine context which made it necessary to gather sources from existing studies which are mostly of foreign origin. Another is, though there were a few studies about technology in the Philippine context, they gave emphasis on the integration of the said technologies to the curriculum and classroom setting. There were however not enough studies in the application of the mentioned technologies. Considering this dilemma, the researchers chose to focus on providing a study that will give emphasis on the perception of FL students in the utilization of internet-based tools in the teaching-learning process, whether in the classroom or personal supplementary learning.

\section{Theoretical Framework}

This study is based on Jerome Bruner's constructivism theory. Cullata, R. (2019) states that "learning is an active process in which learners construct new ideas or concepts based upon their current or past knowledge." This means that students from a new meaning of things around them by evaluating it through their own experience. Hence, this theory puts importance on contextual learning or real-life learning. 
Constructivism emphasizes the discovery of the main idea and derivation of meaning rather than teaching concepts and rules (Aljohani, M. 2017); thus, it is known as discovery learning for students who are involved in problem-solving situations. It only meansthat their past knowledge is required in order for them to understand new concepts. Furthermore, it develops collaboration among learners by discovering new things on their own.

Most IBTs adhere to the characteristics of constructivism. One of which is Influent; a simulation video game where a fictional inventor lost his language learning device. This device is used by the players to locate objects. Each object indicates names, descriptions, and actions known as nouns, adjectives, and verbs which are to be collected and customized to produce a vocabulary list (Powell, D. 2015). The players will then learn basic vocabulary in the target language at their own pace since this video game can be played in any language anyone desires to learn. This tool enables players to hear audio from the native speaker, and it has a function to provide the synonymous words (Three Flip Studios, 2015). Tools such as this provide for learning engagement and require the learners to think critically. It also allows the students to discover things on their own and supply different situations where students' knowledge can be applied to learn new things.

\section{Conceptual Framework}

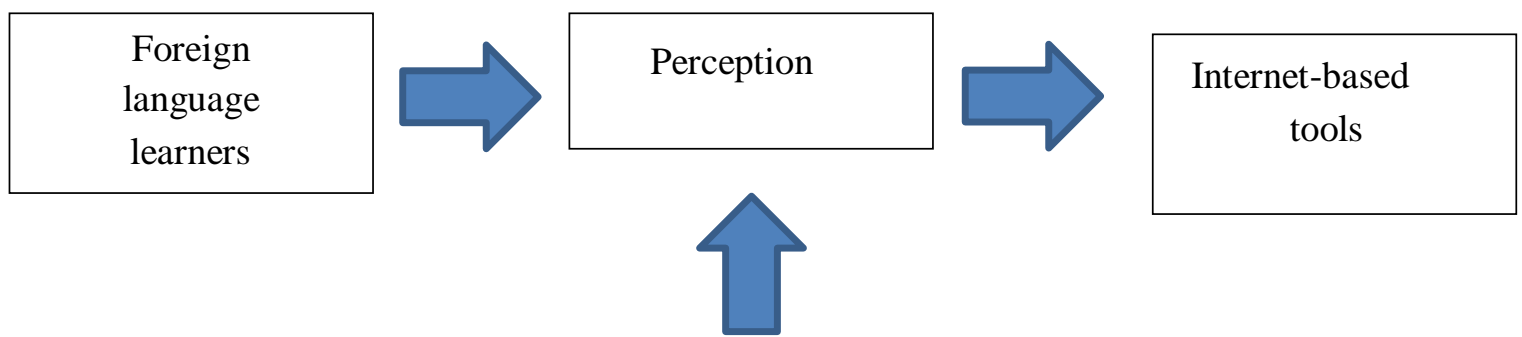

$$
\begin{aligned}
& \text { Knowledge and } \\
& \text { experiences with } \\
& \text { technology }
\end{aligned}
$$

Figure 1: Sequential framework showing the relationship of variables

Figure 1 shows the relationship between the perceptions of respondents (independent variable) regarding the use of the internet-based tools in foreign language learning (dependent variable). The learners' knowledge and experiences with technology serve as a moderating variable that affects their view on the use of internet-based tools. The researchers take into consideration the background of the respondents as foreign language 
learners and their prior experiences and knowledge in using technology which serves as an intervening factor that causes an impact on their perception in the use of internet-based tools. This entails that students' backgrounds have an effect on their perceptions regarding the use of internet-based tools.

\section{Research Questions}

This study aims to discuss the students' perceptions of the strengths and weaknesses of utilizing internet-based tools for foreign language learning. This study seeks to find answers to the following questions:

1. What are the learners' perceived strengths of using internet-based toolsin learning?

2. What are the learners' perceived significant uses of internet-based toolson foreign language learning?

3. What are the learners' perceived problems in the use of internet-basedtools in foreign language learning?

\section{Significance of the Study}

The results of this study will be beneficial and relevant to education stakeholders, namely, the teachers, the University of Makati administrators, students, and other researchers. This study will provide insights to teachers on how to improve foreign languageteaching by integrating internet-based tools. These tools will help teachers for the teaching and learning process to become more interesting and meaningful than the traditional way of teaching language. This study also enables teachers to innovate materials to support the learning of the students using internet-based tools. University of Makati administrators would be encouraged to invest in internet-based technologies and incorporate such technologies to enhance the curriculum. As for the students, this will provide ideas on the tools they can utilize to improve their language learning. This study will benefit the students by providing alternatives to classroom activities in learning foreign languages suitable to cater to different learning styles and will bring advantages to their learning in all areas of education. This will also serve as a basis for other researchers to conduct further studies on the topics under study that might help to further understand the effect of internet-based tools.

\section{Scope and Limitation}

This study is limited only on determining foreign language learners' perceptions of the strengths, significant uses, and problems 
encountered in using the internet-based tools in foreign language learning. The respondents of this study included students from the College of Business and Finance Science during the $1^{\text {st }}$ semester of

S.Y. 2019-2020 studying Mandarin.

\section{Methodology}

\section{Research Design}

This study used a quantitative descriptive research design. This design is administered to distinguish the students' perceptions of the use of internet-based tools in foreign language learning. The variables under this design were mathematically measured such as the frequency and mean and the data analyzed were interpreted; thus, this design is regarded objective.

\section{Locale}

The research was conducted at the University of Makati, also known as UMak, located at J.P Rizal Extension, West Rembo, Makati City, Philippines involving respondents from IV- A Marketing Management students of the College of Business and Finance Science. The University of Makati boasts of its free-for-all facilities including ITC, Multiple Libraries, Speech Lab, Multimedia, and LCD Monitors in every classroom. These facilities provide students with conducive learning environments. These facilities also provide an opportunity for students to use IBTs in their studies.

\section{Participants}

The researchers commissioned an entire class of IV- A Marketing Management consisting of 28 students (12 males and 16 females) from the College of Business and Finance Science (CBFS). The respondents were selected through Purposive Sampling. The researchers chose students from IV- A Marketing Management who were taking a Basic Mandarin course is fit for the topic under study for studying foreign language involved.

\section{Instruments}

The researchers used a self-assessment questionnaire in the form of a Likert scale. The questionnaire was a combination of standardized and researcher-made questionnaires. The standardized questionnaire was adapted from the research of Kia Heirati, J. \& Ahmadi Alashti, L. 
(2015), which they also adapted from the master thesis of Yutdha (2004) and were modified to suit for the study undertaking and for thestudents to understand each question. The researcher-made questionnaire was constructed to answer the research questions under study. The questionnaire composed of three parts as 'Strengths of Using Internet-Based Tools in FLL' which included 23 items, 'Significant Uses of InternetBased Tools in FLL' which had 6 items, and 'Perceived Problems of Foreign Language Learners in Using Internet-Based Tools.' which subsumed 6 items which were randomly placed in the questionnaire. The questionnaire consisted of 35 statements in total. Each statement was answered by putting a checkmark on the scale they thought was most appropriate for them. The scales ranged from 4-strongly agree, 3- agree, 2disagree, and 1- strongly disagree.

\section{Data Gathering Procedure}

Prior to the administration of the questionnaire, the researchers had ameeting with the Dean of the college were the respondents came from to seek permission for the gathering of data, then provided a letter of intent along with a sample of the self-assessment questionnaire used. After the approval, the researchers conducted the survey to the given class. One of the researchers introduced the topic under study, the goal of the research, and explained the structure of the questionnaire and how they are going to answer it. Respondents were also informed that their response will be kept confidential and it is for the sole reason of providing data for the research. The respondents cooperated and intently answered the questionnaire which covered approximately 15 minutes of their time. With that, a total of 28 questionnaires were successfully returned with an equivalent of a 100 percent return rate.

\section{Method of Analysis}

After the data was collected, arranged and tallied, the next step was to analyze the data using mathematical procedures by getting the frequency and mean. The frequency was used to know the total number of respondents who chose a certain scale for each statement. The mean was applied to show the average score of each statement. This was to distinguish which of the strengths of internet-based tools, the significance of internet-based tools and problems encounteredusing internet-based tools in foreign language learning were appealed to the students of the College of Business and Finance Science (CBFS). After analyzing, the researcher interpreted the meaning and implications of the results. 


\section{Results}

This part presents the analysis and presentation of data collected from the self-assessment questionnaire given to IVA Marketing Management students, followed by the interpretation of the findings.

Table 1: Strengths of Using Internet-Based Tools in Learning

\begin{tabular}{ll}
\hline \multicolumn{1}{c}{ Statement } & Mean \\
\hline 1. Promotes Students Higher Order Thinking Skills & 3.36 \\
2. Provides alternative learning approaches & 3.57 \\
3. Makes learning more interesting & 3.39 \\
4. Promotes autonomous learning & 3.29 \\
5. Provides non-native speakers with a rich learningenvironment & 3.18 \\
& \\
6. Helps to achieve future learning purposes & 3.46 \\
7. Alternatives to textbooks & 2.5 \\
13. Provides current information & 3.14 \\
15. Could speed up learning & 3.21 \\
14. Indispensable tool & 3.18 \\
16. Efficiency & 3 \\
17. Convenience & 3.21 \\
18. More beneficial than the traditional method & 3.07 \\
21. Use as an integral part of the educational process & 3.07 \\
22. Retains student attention & 2.93 \\
24. Provides accurate information & 2.75 \\
25. Easy to use & 3.21 \\
26. A reliable source of information & 2.89 \\
27. Makes learning easier & 2.96 \\
30. Provides a wide selection of learning materials & 3.14 \\
31. Accuracy of learning materials & 3.04 \\
33. Easy to understand & 2.82 \\
35. Provides a wide variety of activities & 3.11 \\
\hline
\end{tabular}

Internet-based tools offer a wide range of benefits and advantages to teachers as well as to the learners. Table 1 shows the perception of FL learners regarding the strengths of integrating IBTs to learning in general and learning a foreign language in particular. Internet-based tools as alternative learning approaches have a mean of almost 4.00. It indicates that IBTs can be integrated into the usual teaching and learning process inside the classroom to supply strategies that will address learners' difficulties to learn a foreign language. Meanwhile, the table also shows that IBT helps to achieve future learning purposes of the learners that have the second-highest mean of almost 3.50. However, despite the immense support of internet-based tools, IV-A Marketing Management students believe that 
IBT cannot be an alternative to textbooks which gained the lowest mean. This implies that the emergence of various tools to learn a language, books or any physical reading materials is still preferable and can be helpful to supply knowledge in the teaching and learning process. This result concludes that both IBT and physical reading materials are useful in foreign language learning.

Table 2: Significant Uses of Internet-Based tools in FL learning

\begin{tabular}{ll}
\hline \multicolumn{1}{c}{ Statement } & Mean \\
\hline 8. Source of learning materials & 3.21 \\
20. Creation & 3.18 \\
23. Translation & 3.39 \\
28. Research & 3.14 \\
32. Simulation & 3 \\
34. Application & 2.82 \\
\hline
\end{tabular}

Table 2 shows the learners' perceived uses of internet-based tools in foreign language learning. Translation garnered the highest mean of nearly 4.00, which means that foreign language learners use translation to acquire the vocabularies of a target language (Al-Musawi N. 2014). One way to understand and learn a foreign language is to translate terms from the first language to the target language and vice versa, especially for the respondents who have just started studying basic Mandarin language. They need to familiarize themselves with the basic words and grammar formation of the language. On the other hand, the use of internet-based tools for the application of what has been learned received the lowest mean of less than

3.00. This may be because the respondents are studying basic Mandarin language, which means that, their only focus is on building their vocabularies and basic daily conversation and not on the application of the language itself.

Table 3: Problems Perceived by FL learners in using IBTs

\begin{tabular}{ll}
\hline \multicolumn{1}{c}{ Statement } & Mean \\
\hline 9. Lacks competency in using internet-based tools & 3.11 \\
10. Competent to use internet-based materials & 3.11 \\
11. Needs more technology training & 2.96 \\
12. Lack of knowledge on integration & 3.18 \\
19. Cannot improve the quality of learning & 2.64 \\
29. The validity of learning materials & 3.07 \\
\hline
\end{tabular}

Table 3 shows the problems perceived by students regarding the use of internet-based tools in FL learning. As can be seen, the lack of knowledge in the integration of internet-based tools in learning got the highest mean of 
almost 3.20. This, therefore, shows that learners are aware of the deficiency of their knowledge and abilities about technology which affects their confidence in integrating IBT in their learning. Limited knowledge of the use of technology in general also contributes to the fact that learners are having a hard time integrating internet tools. On the contrary, the statement about IBTs inability to improve the quality of learning accumulated the lowest mean of not more than 2.65. This implies that learners agree that internet- based tools, with its features of providing various activities and the vast amount of learning materials, are able to promote understanding of the concept that leads to the better acquisition of the target language. Internet- based tools provide opportunities for the learners to improve and be more skilled through its integration to the teaching and learning process. However, with the lack of knowledge with the integration, learners will find internet-based tools ineffective in improving the quality of learning.

\section{Discussion}

The results of the study conducted show the students' perception regarding the strengths, significant uses and the problems posed by utilizing internet-based tools in learning a foreign language. Based on the survey conducted, respondents from IV-AMM believe that internet- based tools promote learners' higher-order thinking skills. This is an indicator of the respondents' positive regard for IBT in its ability to hone their critical thinking skills and creativity. Moreover, internet- based tools are perceived as a provider of alternative learning approaches to address the different learning needs of students, therefore allowing for autonomous learning. This finding supports the views of Gallo-Crail, R., and Zerwekh, R. (2002) which cites the significance of having learning strategies to individual language learning efficiency. Furthermore, they also consider as one of the strengths of the said tools is its ability to be incorporated in other learning purposes aside from language learning making it beneficial to learning in general.

As of the significant uses of internet-based tools, respondents most often use the internet for translation purposes compared to other uses of IBTs like research, simulation, application, and creation. This can be attributed to the idea that in their foreign language course, Basic Mandarin, the lessons are more focused on learning vocabularies and basic conversational language. They are giving emphasis on acquiring the vocabularies of mandarin before they can proceed to the more complex communicative competencies of the language. That is also the reason why Google Translate is one of the most used IBT among FL learners that were surveyed in this study. 
The study also shows findings on the problems perceived by FL learners in incorporating IBT in their learning. Majority of the respondents showed interest in integrating IBT in their learning, yet also admits that they lack the skills and competencies required to thoroughly take advantage of the technology. It is closely related to the findings garnered by Arikan, A. and Ozel, A. (2015) which conducted the study to EFL instructors from Schools of Foreign languages of different universities in Turkey. The study shows that EFLinstructors have positive attitudes toward the use of Internet and Web

2.0 yet; they are not using them sufficiently in their teaching and are not satisfied with the little opportunity their schools give them to hone their skills in using the said technologies.

One surprising finding the researchers learned is despite the prevalent use of gadgets and the internet; students are still not united with the notion that these technologies have the ability to completely replace textbooks. These may be due to the fact that information gathered from textbooks and other printed media go through rigorous measures to ensure its reliability as against the dangers of getting faulty information which is undeniably common in the World Wide Web.

\section{Conclusion}

The findings of this study revealed a number of significant insights regarding the learners' perception in the use of IBTs in learning. Upon carefully examining and interpreting the results collated, the researchers came to the conclusion that FL learners have a generally positive perception towards the use of internet-based tools whether it be for classroom teaching or personal supplementary learning. The results of this study showed that the respondents have a high expectation of the benefits of integrating IBTs to their FL classes. Unfortunately, they rarelyincorporate technology in their daily classroom lectures and activities. They also admit that they depend heavily on textbooks and classroom lectures instead of looking for more innovative ways of learning. Furthermore, FL learners feel that there were not opportunities for them to utilize the said tools. Some students have the intention of further integrating IBTs in their other learning tasks. However, the findings also showed that the respondents feel that they are lacking the necessary knowledge and skills in technology integration to fully take advantage of the said technology. 


\section{Recommendation}

Having understood the students' view on the strengths, significant uses and problems with using IBTs in FL learning the researchers found certain areas that need to be given attention for them to achieve the competencies required in LL and fully take advantage of the available technologies provided for them by the university, specifically the Information Technology Center and Computer Labs. First, they should be provided with more opportunities to be exposed to IBTs by integrating it into their lessons. The learners recognize their lack of knowledge and skills in using IBTs. Therefore, a seminar or workshop focusing on the topic of IBT integration and application can helpsignificantly to aid the learners in this concern. Teachers and instructors should also be equipped with the knowledge and skills in IBT which will only be achieved if they will be given proper training in the use of these technologies. They will benefit from attending Educational Technology (EdTech) conferences and conventions which will enhance their knowledge and motivation to incorporate IBTs in their teaching. Lastly, to the next researchers who may be interested in delving deeper into this subject to focus on discovering the types of IBT which can be integrated into FL learning in the classroom setting. Tools that can be used by the FL professors as an alternative or supplement to lectures to properly address the different learning stylesand needs of FL learners. 


\section{References}

Ahmadi, M. (2018). The use of technology in English language learning: A literature review. Retrieved from http://ijreeonline.com/article-1-120- en.pdf

Aljohani, M. (2017). Principles of constructivism in foreign languageteaching. University of Tabuk, Saudi. David Publishing.

Al-Musawi N. (2014). Strategic use of translation in learning English as a foreign language (EFL) among Bahrain university students. University of Bahrain. Ammons Scientific LTD.

Calderon, J. \& Gonzales, E. (1993). Methods of research and thesis writing. Valenzuela, Metro Manila. National Book Store.

Cullata, R. (2019). Constructivist theory. Instructional Design Org. Retrievedfrom https://www.instructionaldesign.org/theories/constructivist/

Evans, M. (2011). Foreign Language Learning with Digital Technology. Illinois, USA. Continuum Publishing Corporation.

Gallo-Crail, R., \& Zerwekh, R. (2002). Language learning and the Intenet: Student strategies in vocabulary acquisition. Northern IllinoisUniversity.

Gençlter, B. (2015). How does technology affect language learning processat an early age. Procedia-Social and Behavioral Sciences. Elsevier Ltd.

Gupta, P. (2017). Major challenges for technology integration in theclassrooms. EdTechReview. Retrieved from:https://edtechreview.in/trends-insights/insights/2999-challenges- technology-integration-in-theclassroom

Jabeen, S. \& Thomas, A. (2015). Effectiveness of online language learning. World Congress on Engineering and Computer Science. San Francisco,USA.

Kia Heirati, J. \& Ahmadi Alashti, L. (2015). Attitudes toward using theinternet for language learning: a case of Iranian English teachers and learners. International Journal of Research Studies in Educational Technology. Iran. 
Mbodila M., Jones, T., \& Muhandji K. (2013). Integration of ICT in Education:Key Challenges. International Journal of Emerging Technology and Advanced Engineering.

Moeller, A. \& Catalano, T. (2015). Foreign language teaching and learning.

University of Nebraska-Lincoln, USA.

Mohammadia, N., Ghorbanib V., \& Hamidiab, F. (2010). Effects of e-learningon Language Learning. Procedia Computer Science. Elsevier Ltd.

Ozel, A. \& Arikan, A. (2015). The use of the internet and web 2.0 toolsamong EFL instructors. Mediterranean Journal of Humanities.

Powell, D. (2015). Get your game on! 13 fun foreign language FluentU: Foreign Language Immersion Online. Retrieved from https://fluenu.com/blog/foreign-language-games/

Three Flip Studios (2015). Influent-language learning game: Kickstarter video. Retrieved from https://www.youtube.com/watch?v=BXVBQxbXbI4

Oxford University Press (2019). Language learning. Retrieved from encyclopedia.com/humanities-almanacs-transcripts-and-Imaps/language learning 